\title{
Van sleutelen aan het stelsel naar bouwen aan inhoudelijke vernieuwing
}

\section{Saskia Wijsbroek, Marije Kesselring en Dorien Graas*}

De Jeugdwet uit 2015 heeft nog niet gebracht wat ervan verwacht werd, zo blijkt uit de evaluatie van de wet in 2018 en ook uit de recent uitgekomen rapporten van de Inspectie Gezondheidszorg en Jeugd (IGJ) en de Inspectie Justitie en Veiligheid (IJenV) (2019a, 2019b). Veel van de ervaren tekortkomingen van voor 2015 bestaan anno 2019 nog. Om de zorg voor jeugd inhoudelijk te vernieuwen lijkt meer nodig dan alleen geld of een stelselwijziging, namelijk aandacht voor de vijf samenhangende fundamentele ingrediënten van een goed functionerend jeugdstelsel (NJi 2019b). Als eerste ingrediënt wordt een sterke basis genoemd. Een sterk pedagogisch fundament of 'pedagogische civil society' wordt, ook in internationaal onderzoek, gezien als een cruciaal ingrediënt van het stelsel. Ook de Raad voor Maatschappelijke Ontwikkeling (RMO) gaf al vóór de stelselwijziging aan dat het vooral moet gaan om een inhoudelijke stelselwijziging (RMO 2011, 2012). In dit essay geven we een beknopte analyse van de transitie en de transformatie in de jeugdsector en gaan we nader in op de 'pedagogische civil society' binnen de context van een samenhangend jeugdstelsel.

* Dr. S.A.M. Wijsbroek werkt als lector Jeugd bij het Kenniscentrum Sociale Innovatie aan de Hogeschool Utrecht en als universitair docent bij de onderzoeksgroep Jeugd en Gezin aan de Universiteit Utrecht. Dr. M. Kesselring is als onderzoeker verbonden aan het lectoraat Jeugd bij het Kenniscentrum Sociale Innovatie aan de Hogeschool Utrecht. Dr. T.A.M. Graas werkt als lector Jeugd bij het Kenniscentrum Gezondheid en Welzijn aan de Hogeschool Windesheim. 


\section{De 'staat van de jeugd'}

Veel artikelen over jeugdhulp of jeugdzorg ${ }^{1}$ starten met de constatering dat het met de overgrote meerderheid van de jeugdigen in Nederland over het algemeen goed gaat. In internationaal vergelijkend onderzoek blijkt dat de Nederlandse jeugd hoog scoort op welbevinden en gezondheid, en tot de gelukkigste ter wereld behoort (UNICEF Office of Research 2013; Stevens e.a. 2018). Tegelijkertijd staat Nederland ook in de top van de lijsten met hoogste percentages (specialistische) jeugdhulp en residentiële plaatsingen van kinderen.

Een van de aanleidingen voor de invoering van de Jeugdwet was het hoge zorggebruik. De cijfers laten zien dat in de eerste jaren na de invoering van de wet het zorggebruik juist is toegenomen. In 2015 ontving $10 \%$ van de jeugdigen jeugdhulp (343.100 jeugdigen) en 10,8\% (370.410 jeugdigen) jeugdzorg. In 2018 was dit $11,7 \%$ jeugdhulp (396.235 jeugdigen) en 12,2\% jeugdzorg (412.660 jeugdigen) (CBS 2019a). In het eerste halfjaar van 2019 kregen volgens voorlopige cijfers 366.000 jeugdigen jeugdzorg (CBS 2019b). In de eerste helft van 2015 waren dit 319.000 jeugdigen, dit betreft een toename van bijna $15 \%$. Ook het vijfde jaar na de transitie is gestart met een toename van zorggebruik. Afgezien van de zorgen over de enorme kosten die de toename van zorg met zich meebrengt, staat ook de kwaliteit van de hulpverlening ernstig onder druk, zoals blijkt uit het onlangs verschenen inspectierapporten Kwetsbare kinderen onvoldoende beschermd (IGJ \& IJenV 2019a) en Jeugdbeschermingsketen in gevaar (IGJ \& IJenV 2019b). Is er dan zoveel mis met de Jeugdwet of doen we met $z$ 'n allen de verkeerde dingen? Of beide?

1 Het CBS hanteert de term jeugdhulp voor alle vormen van hulp en ondersteuning (lvb, opvoedvragen, opvoedhulp, jeugd-Ivb en jeugd-ggz), variërend van licht ambulant (vaak vanuit een wijkteam, waaronder mogelijk ook gewone opvoedvragen) tot intensieve, zeer gespecialiseerde zorg in een al dan niet gesloten setting (jeugdzorgplus). De term jeugdzorg is de verzamelnaam voor jeugdhulp, jeugdbescherming en jeugdreclassering (NJi 2019a). 


\section{Transitie en transformatie}

Met de invoering van de Jeugdwet in 2015 werd de zorg voor jeugdigen en ouders ${ }^{2}$ gedecentraliseerd van het Rijk en provincies naar gemeenten. De nieuwe Jeugdwet had als doel het jeugdstelsel te vereenvoudigen en de hulp efficiënter en effectiever te maken. De decentralisatie betrof het hele spectrum aan ondersteuning en hulp. Zo werden de gemeenten verantwoordelijk voor:

1. versterking van een positief opvoed- en opgroeiklimaat;

2. preventie;

3. vroegsignalering;

4. basis- en specialistische jeugdhulp (jeugd- en opvoedhulp, jeugd-

(l)vb: jeugdigen met een (licht) verstandelijke beperking, jeugd-ggz);

5. de uitvoering van kinderbescherming en jeugdreclassering.

Binnen de Jeugdwet zou het Rijk de noodzakelijke randvoorwaarden blijven creëren en een ondersteunende rol vervullen door het ontwikkelen van monitorinstrumenten, het geven van handreikingen en het stimuleren van zorg voor kwaliteit en innovatie. Met de Jeugdwet werd tevens een jeugdhulpplicht voor gemeenten ingevoerd en kwam het wettelijk recht op zorg voor jeugdigen te vervallen. De invoering van de decentralisatie van de jeugdhulp naar de gemeenten ging gepaard met een reductie van $15 \%$ op het budget voor jeugdhulp.

Naast de bestuurlijke en financiële verschuiving (de transitie) werden ook hervormingen in de vorm van inhoudelijke vernieuwing beoogd (de transformatie), gericht op preventie, wijkgericht werken en 'burgerkracht'. Voor deze inhoudelijke vernieuwing van de jeugdsector waren de zogenoemde 'transformatiedoelen' leidend: ${ }^{3}$

- preventie en uitgaan van eigen verantwoordelijkheid en eigen mogelijkheden van jeugdigen en hun ouders, met inzet van hun sociale netwerk;

- demedicaliseren, ontzorgen en normaliseren door onder meer het opvoedkundig klimaat te versterken in gezinnen, wijken, scholen en in voorzieningen als kinderopvang en peuterspeelzalen;

2 Met de term 'jeugdigen' worden kinderen en jongeren van 0 tot 18 jaar bedoeld. Met 'ouders' worden ook wettelijk verantwoordelijke verzorgers bedoeld. Met 'gezinnen' worden uiteenlopende vormen van samenwonen van een of meer ouders of wettelijk verantwoordelijke verzorgers met een of meer jeugdigen bedoeld.

3 Rijksoverheid, Memorie van toelichting bij de Jeugdwet 2013, p.2, www.rijksoverheid.nl/ documenten/kamerstukken/2013/07/01/memorie-van-toelichting-bij-de-jeugdwet. 
- eerder de juiste hulp op maat bieden om het beroep op dure gespecialiseerde hulp te verminderen;

- integrale hulp aan gezinnen volgens het uitgangspunt 'één gezin, één plan, één regisseur';

- betere samenwerking en innovaties in ondersteuning, hulp en zorg aan jeugdigen en gezinnen door ontschotting van budgetten;

- meer ruimte voor professionals om de juiste hulp te bieden door vermindering van regeldruk;

- professionals weten sociale netwerken in de omgeving van het gezin in te schakelen en kunnen samenwerken met vrijwilligers en familieleden en hun kracht benutten.

\section{Eerste evaluatie Jeugdwet}

Een belangrijk overkoepelend doel van de transitie en transformatie was dat jeugdigen en ouders tijdig passende ondersteuning en hulp zouden ontvangen. Gemeenten hadden hierbij de regierol gekregen vanuit de gedachte dat zij, dicht bij de inwoners, maatwerk konden leveren en daarmee de kwaliteit van de jeugdhulp zouden kunnen verbeteren.

De eerste evaluatie van de Jeugdwet in 2018 toonde echter aan dat de beoogde transformatie, gericht op de realisatie van de inhoudelijke vernieuwing, voor het grootste deel nog vorm moest gaan krijgen (Friele e.a. 2018). De evaluatie van de Jeugdwet, nadrukkelijk niet van de jeugdhulp, dient te worden geïnterpreteerd als een tussentijdse evaluatie. Allereerst wordt geconstateerd dat de vraag naar hulp nog niet is afgenomen. Ook is het de gemeenten nog onvoldoende gelukt de jeugdhulp dichter bij de leefwereld van jeugdigen en gezinnen te brengen: bijvoorbeeld een samenwerking van onderwijs en jeugdhulp op school of specialistische jeugdhulp in de wijk in plaats van in een grote stad dertig kilometer verderop. Er is binnen de gemeenten en de jeugdregio's ook (nog) niet zichtbaar meer ingezet op preventie. Een cruciale bevinding is dat juist gezinnen met complexe en meervoudige hulpvragen minder goed de weg weten te vinden naar jeugdhulp dan gezinnen met minder complexe en enkelvoudige vragen. In de toegang tot hulp, de samenhang in het creëren van passende hulp en de samenwerking tussen organisaties voor (specialistische) jeugdhulp zijn daarom grote verbeteringen nodig (Friele e.a. 2018). 
Kortom, veel problemen die al speelden voor de invoering van de Jeugdwet zijn er nog en de voorziene rust voor de jeugdsector is er nog niet (Stevens e.a. 2018). Met de decentralisatie van de jeugdhulp zijn gemeenten nu allerlei rollen gaan vervullen als financier, eindverantwoordelijke, controleur en toegangspoort tot jeugdhulp. Daarmee is het systeem voor de basisvoorzieningen in de buurt, voor de organisaties voor (specialistische) jeugdhulp en voor de professionals uitermate complex geworden: alles en iedereen is van elkaar afhankelijk geworden. Terwijl met de transitie en transformatie werd beoogd de jeugdhulp dichter bij de gezinnen te organiseren, waren veel jeugdhulpaanbieders (vanwege het dreigende 'omvallen') genoodzaakt te fuseren en (landelijk) groter te worden. Verschillende transformatiedoelen kwamen daardoor in de knel, zoals meer ruimte geven aan professionals, vermindering van regeldruk, het normaliseren en ontzorgen en het versterken van het opvoedkundig klimaat. Jeugdzorg is, alle goede bedoelingen ten spijt, steeds meer een verdienmodel geworden (Graas e.a. 2018).

\section{Agenda van aanpak}

De evaluatie van de Jeugdwet leverde een agenda op voor een gezamenlijke aanpak door het Rijk, de gemeenten en praktijkorganisaties in jeugdhulp om de transformatie verder te brengen. Het kabinet reageerde begin 2018 op de eerste evaluatie van de Jeugdwet met het actieprogramma Zorg voor de Jeugd. ${ }^{4}$ Later in 2018 stelden de Vereniging van Nederlandse Gemeenten (VNG) en het ministerie van Volksgezondheid, Welzijn en Sport (VWS) het Transformatiefonds (VNG 2018) beschikbaar en in 2019 opende ZonMw de subsidieaanvraag Regionale kenniswerkplaatsen jeugd. ${ }^{5}$

In het actieprogramma Zorg voor de Jeugd zijn de plannen voor de jeugdhulp ondergebracht in zes lijnen, met als overkoepelend doel 'tijdig passende hulp voor jeugdigen en ouders'. De zes programmalijnen zijn (zie noot 3):

1. alle kinderen de kans bieden zich te ontwikkelen;

2. meer kinderen zo thuis mogelijk laten opgroeien;

4 Zie www.rijksoverheid.nl>documenten>rapporten>2018/04/01.

5 Zie www.zonmw.nl>jeugd $>$ progammas $>$ programma-detail-regionalekenniswerkplaatsen-jeugd. 
3. kwetsbare kinderen beter op weg helpen zelfstandig te worden;

4. jeugdigen beter beschermen als hun ontwikkeling gevaar loopt;

5 . betere toegang tot de jeugdhulp;

6 . investeren in vakmanschap.

Om een impuls te geven aan de vernieuwing van het jeugdhulpstelsel hebben alle 42 jeugdregio's een regionaal transformatieplan gehonoreerd gekregen. ${ }^{6}$ In een regionale kenniswerkplaats jeugd wordt vanuit verschillende perspectieven (praktijk, ouders, jeugdigen, beleid, opleidingen voor de professionals van de toekomst, en onderzoek) samengewerkt aan regionale maatschappelijke vraagstukken.

Hiermee is van de kant van de Rijksoverheid geld vrijgemaakt om te kunnen werken (buiten alle aanbestedingen om) aan de transformatiedoelen van de Jeugdwet. Een belangrijk doel van de hervormingen is dat jeugdigen en gezinnen tijdig passende hulp ('hulp op maat') kunnen krijgen. In de overgrote meerderheid van de gemeenten zijn sociale wijkteams opgericht voor het bieden van basishulp, ofwel in teams voor alle inwoners van 0 tot 100 jaar, ofwel in aparte teams voor jeugdigen en gezinnen, en volwassenen. Bij de professionals in deze sociale wijkteams kunnen jeugdigen en ouders terecht voor vragen over opgroeien en opvoeden. Deze laagdrempelig toegankelijke lokale jeugdhulp zou moeten gaan bijdragen aan een afname van het grote beroep op de specialistische hulp. Tot zover het actieplan naar aanleiding van de eerste evaluatie van de nieuwe Jeugdwet.

\section{Nieuwe ontwikkelingen}

In de afgelopen jaren zijn enkele nieuwe ontwikkelingen waar te nemen binnen de lokale jeugdhulp die zouden kunnen bijdragen aan de beoogde transformatie. Zo hebben sommige gemeenten ervoor gekozen om niet alleen hbo-opgeleide generalistische medewerkers in de teams op te nemen, maar daarnaast ook gespecialiseerde academisch opgeleide professionals. In de jeugdregio Amsterdam maken gedragswetenschappers deel uit van de Ouder- en Kindteams om snel en met de juiste hulp zo goed mogelijk te kunnen aansluiten bij de 
vraag van jeugdigen en gezinnen. ${ }^{7}$ Waar mogelijk wordt lichte ambulante hulp verleend, maar zo nodig ook intensievere hulp.

Een tweede voorbeeld is te vinden in verschillende regio's, waar wordt ingezet op een sterke, intensieve samenwerking van huisartsen, jeugdartsen en -verpleegkundigen met professionals in de basis- en specialistische hulp binnen de wijken met als doel om de specialistische hulp dichter bij de mensen te positioneren. Zo gaan in jeugdregio Utrecht Stad 'buurtgerichte specialistische teams' per 1 januari 2020 van start om jeugdhulp in de wijken aan te bieden, dit na een succesvolle pilot. $^{8}$

\section{Kwetsbare kinderen onvoldoende beschermd}

Lopende deze initiatieven verschenen begin november 2019 gelijktijdig het inspectierapport Kwetsbare kinderen onvoldoende beschermd. Toezicht bij de jeugdbescherming en jeugdreclassering en Signalement Kwetsbare kinderen onvoldoende beschermd. Jeugdbeschermingsketen in gevaar, beide van de IGJ en de IJenV.

De inspecties constateren dat de gecertificeerde instellingen die deze jeugdigen namens de overheid beschermen hun opdracht onvoldoende kunnen uitvoeren. Oorzakelijke factoren die een belangrijke rol spelen, zijn de zwaarte en complexiteit van de problemen, onvoldoende beschikbaarheid van direct inzetbare, passende hulp, personele kwesties (tekorten, verloop, verzuim) en financiële onzekerheid bij de instellingen. Net als in de evaluatie op de Jeugdwet bleek juist de groep jeugdigen, ouders en gezinnen met de meeste kwetsbaarheden en complexe vragen en problemen niet tijdig gebruik te kunnen maken van passende hulp.

Het kabinet heeft laten weten de jeugdsector beter te willen gaan ordenen in de vorm van dwang om gemeenten en organisaties van jeugden opvoedhulp meer en beter te laten samenwerken. Een aantal opgaven zou voortaan regionaal georganiseerd moeten gaan worden: pleegzorg, gesloten jeugdzorg, en specialistische zorg voor jeugdigen met anorexia nervosa. Hiermee lijkt het erop dat het kabinet wederom de pijlen richt op bestuurlijke en organisatorische veranderingen van

7 Zie Gemeente Amsterdam, Jeugdpsycholoog Ouder- en Kindteams Amsterdam, www.oktamsterdam.nl > uploads $>2017 / 03>$ factsheet.

8 Gemeente Utrecht, Pilots buurtgerichte specialistische jeugdhulp, https:// zorgprofessionals.utrecht.nl. 
het stelsel en niet op een inhoudelijke koerswijziging waarvoor al voor de invoering van de Jeugdwet werd gepleit (RMO 2011, 2012).

\section{Een beter functionerend jeugdstelsel voor alle jeugdigen}

Volgens het VN-Verdrag inzake de Rechten van het Kind dienen alle jeugdigen de kans te krijgen om mee te doen en veilig, gezond en kansrijk te kunnen opgroeien. Stappen in afgelopen jaren zijn vooral gericht op het verbeteren van de basis- en specialistische jeugdhulp en het vergroten van hun onderlinge samenhang binnen de nieuwe sociale wijkteams en de specialistische zorg. De bezuinigingsoperatie, de organisatie van de jeugdhulp in sociale wijkteams, de ervaren versnippering van de specialistische jeugdhulp, de toegenomen complexiteit van de hulpvragen en daarmee de vraag om specialistische jeugdhulp, zijn hieraan onderliggend. De aandacht gaat hiermee uit naar dat deel van de jeugdsector waarin de hulp georganiseerd is. Zorg voor jeugd betreft echter alle jeugdigen, ouders en gezinnen.

In het kader van de beoogde inhoudelijke vernieuwing is het daarom de vraag waarom de aandacht alleen uitgaat naar het verder verbeteren van de professionele basis- en specialistische hulp aan jeugdigen en gezinnen. Er wordt nauwelijks aandacht besteed aan de noodzakelijke vijf ingrediënten die, ook in internationaal onderzoek, in hun onderlinge samenhang een goed functionerend jeugdstelsel blijken te vormen voor alle jeugdigen en ouders (NJi 2019b). Fundamenteel voor zo'n stelsel is een gedeelde visie op opgroeien en opvoeden, op de kwaliteit van jeugdhulp, -bescherming en -reclassering, op verwachtingen van de jeugdzorg en op de verbetering van het jeugdstelsel. Hiervoor zouden burgers, professionals en politiek zich samen moeten buigen over vraagstukken als: Wat zijn belangrijke waarden in het opvoeden van jeugdigen? Hoe denken we over de ervaren prestatiedruk door jongeren? Wat is er nodig om alle kinderen kansrijk op te laten groeien? Waar moet het geld naartoe gaan? Wat verstaan we onder kwaliteit van zorg?

Een échte vernieuwing zou kunnen worden gerealiseerd door te investeren in de vijf ingrediënten van het stelsel:

1. een versterking van de pedagogische basis: een positief pedagogisch klimaat in gezin, buurt, kinderopvang, school, vrijetijdsverenigingen en de online wereld waarin jeugdigen verkeren; 
2. veel aandacht voor preventie (universeel, selectief, geïndiceerd) binnen het jeugdstelsel. Universele preventie is voor ouders en gezinnen waarbij geen sprake is van risico's. Qua voorzieningen valt dan te denken aan opvoedingsondersteuning voor alle ouders en gezinnen of vrijblijvend advies. Selectieve preventie wordt aangeboden aan specifieke groepen ouders of gezinnen, die worden geselecteerd op basis van risicokenmerken, zoals gezinnen met een lage sociaaleconomische status of onvolledige gezinnen. Geïndiceerde preventie betreft jeugdigen, ouders of gezinnen bij wie sprake is van een vastgesteld risico bij de ouder en/of jeugdige door bijvoorbeeld bestaand ongewenst probleemgedrag of een zware opvoedbelasting of opvoedstress;

3. verbetering van ondersteuning in de eerste lijn, zoals bij de jeugdgezondheid, de praktijkondersteuner van de huisarts, jongerenwerk of schoolmaatschappelijk werk;

4. intensieve hulp binnen jeugdzorg, met duurzame effecten;

5 . het vijfde en laatste ingrediënt in de verbetering van het jeugdstelsel is een sterke focus op de aanpak van concrete lokale en (boven)regionale maatschappelijke vraagstukken (NJi 2019b).

Voorbeelden uit binnen- en buitenland maken duidelijk dat de eerste vier ingrediënten helpen om een goed functionerend jeugdstelsel te bouwen en daarmee tevens het zorggebruik te verminderen. Cruciaal daarbij is de onderlinge samenhang tussen de ingrediënten: hulp met duurzame effecten kan bijvoorbeeld niet bereikt worden zonder versterking van de pedagogische basis. De vier ingrediënten zijn niet van elkaar te scheiden.

\section{Een sterke pedagogische civil society}

Een sterke pedagogische basis betreft het versterken van de opvoednetwerken waarin jeugdigen opgroeien en waarin ouders en medeopvoeders zich inzetten voor het grootbrengen van jeugdigen: de pedagogische civil society (De Winter 2008, 2012; Hilhorst \& Zonneveld 2013; Kesselring 2016).

Het concept werd in 2008 door Micha de Winter geïntroduceerd en is gebaseerd op uiteenlopende wetenschappelijke benaderingen, zoals het bio-ecologisch systeemtheoretisch denkmodel (Bronfenbrenner 
1977), de positieve psychologie (Seligman e.a. 2007) en empowerment (Boumans 2012; Freire 1970; Van Regenmortel 2015).

De pedagogische civil society heeft betrekking op de betekenis die vrijwillige verbanden en onderlinge betrokkenheid van medeopvoeders kunnen hebben voor opvoeden en opgroeien van jeugdigen, in lijn met het Afrikaanse gezegde 'It takes a village to raise a child'. Medeopvoeders zijn dan de volwassenen uit het netwerk van het gezin die de gezinsleden vanuit een formele of informele rol ondersteunen bij opgroeien en opvoeden. Familieleden, buren, vrienden en ouders van andere kinderen zijn informele medeopvoeders, professionals in de pedagogische basisvoorzieningen zoals kinderopvang, school en jongerenwerk zijn formele medeopvoeders. Betrokkenheid en steun van medeopvoeders blijken positief bij te dragen aan het opgroeien en opvoeden van jeugdigen (Benson e.a. 1998; Ince e.a. 2018). Zo werd uit onderzoek duidelijk dat de betrokkenheid van medeopvoeders bijdraagt aan betere schoolprestaties (Putnam 2000), meer zelfvertrouwen (Lerner e.a. 2005) en minder delinquentie en middelengebruik (Resnick e.a. 1997; Scales e.a. 2001).

In Nederland wordt al jarenlang met regelmaat geconstateerd dat de traditionele steunstructuren grotendeels verdwenen zijn en familie, vrienden, buren en kennissen steeds minder betrokken zijn bij elkaars gezinsleven. Daardoor is opvoeden steeds meer een individuele aangelegenheid geworden en zijn gezinnen steeds minder sociaal ingebed.

De RMO - en nu ook de Raad voor de Volksgezondheid en Samenleving - en het Nederlands Jeugdinstituut, ondersteund door een groot aantal wetenschappers (onder meer de pedagogen De Winter, Hermanns, Kesselring en Van Montfoort) pleiten al vanaf 2000 voor het versterken van de sociale netwerken en steunstructuren van gezinnen. Ook de toenmalige minister voor Jeugd en Gezin, Rouvoet, benadrukte het belang van de sociale netwerken voor gezinnen. ZonMw stelde subsidie beschikbaar voor wetenschappelijk onderzoek naar 'Gewoon opvoeden' (zie Kesselring e.a. 2013). Ouders die met elkaar meedenken over alledaagse opvoedvragen, pedagogisch medewerkers en leerkrachten die met ouders meedenken over gedrag van kinderen in een specifieke leeftijdsfase zijn voorbeelden van manieren waarop ouders en gezinnen meer in gezamenlijkheid op kunnen trekken rondom het ontwikkelen en opvoeden van hun kinderen. Met andere woorden: 
'Schep een omgeving waar vanzelfsprekende steun is voor ouders, kinderen en jongeren' (Graas e.a. 2018, p. 272).

\section{Tot slot}

De gemeenten hebben de opdracht de zorg voor alle jeugdigen dichter bij de leefwereld van jeugdigen en hun opvoeders te brengen. Tot nu toe lijkt echter de reorganisatie van de basis, de pedagogische civil society, sterk achter te blijven bij alle aandacht die uitgaat naar de jeugdhulp. Visie op en sturing van de versterking van de pedagogische basis zijn in veel gemeenten niet geëxpliciteerd en niet gekoppeld aan de transformatiedoelen.

Niet de vraag of het al dan niet goed gaat met een jeugdige, ouders of gezin, maar de vraag wat jeugdigen, opvoeders of gezinnen nodig hebben, dient bepalend te zijn als het overkoepelende doel is om alle jeugdigen optimale mogelijkheden te bieden om gezond, veilig en kansrijk op te groeien. Dit vraagt om een integrale benadering, waarin het bevorderen van mogelijkheden en beschermende factoren en het beperken van risico's in elkaars verlengde liggen. Het stimuleren van participatie en het voorkomen van uitval worden daarmee als maatschappelijke opdracht even belangrijk als het bieden van hulp en bescherming (Wijsbroek \& De Winter 2017). Om bij te dragen aan een beter functionerend jeugdstelsel is het een gezamenlijke opgave om het verbeteren van de jeugdzorg en het versterken van de pedagogische basis, hand in hand, in voortdurende onderlinge afstemming, gezamenlijk te laten plaatsvinden. 


\section{Literatuur}

\section{Benson e.a. 1998}

P.L. Benson, N. Leffert, P.C. Scales \& D.A. Blyth, 'Beyond the "village" rhetoric. Creating healthy communities for children and adolescents', Applied Developmental Science (2) 1998, afl. 3, p. 138-159.

\section{Bot e.a. 2013}

S. Bot, S. van Roos, K. Sadiraj, A. Keuzenkamp, A. van den Broek \& E. Kleijnen, Terecht in de jeugdzorg. Voorspellers van kind-en opvoedingsproblematiek en jeugdzorggebruik, Den Haag: Sociaal en Cultureel Planbureau 2013.

\section{Boumans 2012}

J. Boumans, Naar het hart van empowerment. Een onderzoek naar de grondslagen van empowerment voor kwetsbare groepen, 2012, www.movisie.nl/ sites/default/files/alfrescofiles/ Naar-het-hart-van-empower ment-deel-1\%20[MOV-99038141.0].pdf.

\section{Bronfenbrenner 1977}

U. Bronfenbrenner, 'Toward an experimental ecology of human development', American Psychologist (32) 1977, afl. 7, p. 513-531.

\section{CBS 2018}

CBS, Jeugdmonitor, Den Haag: Centraal Bureau voor de Statistiek, 2018, www.cbs.jeugdmonitor.nl.

\section{CBS 2019a}

CBS, Cijfers over jeugd en opvoeding, Den Haag: Centraal Bureau voor de Statistiek, 2019, www.nji.nl/nl/Databank/Cijfersover-Jeugd-en-Opvoeding/ Cijfers-per-Voorziening/AanbodJeugdhulp.

\section{CBS 2019b}

CBS, Jeugdhulp 1e half jaar 2019, Den Haag: Centraal Bureau voor de Statistiek, 2019, www.cbs.nl>nlnl $>$ publicatie $>2019>$ jeugdhulp1e-halfjaar-2019.

\section{Clarijs 2017}

R. Clarijs, Handboek jeugdbeleid en jeugdhulp, Amsterdam: SWP 2017.

\section{Freire 1970}

P. Freire, Pedagogy of the oppressed, New York: Continuum 1970, www.msu.ac.zw/elearning/ material/1335344125freire pedagogy of the oppressed.pdf.

\section{Friele e.a. 2018}

R.D. Friele, M.R. Bruning, I.L.W. Bastiaanssen, R. de Boer e.a., Eerste evaluatie Jeugdwet: na de transitie nu de transformatie. Den Haag: ZonMw 2018. 


\section{Graas e.a. 2018}

D. Graas, A. de Klein, J. Stevens, T. Jansen e.a., 'Écht doen wat nodig is: een uitnodiging', in: D. Graas, A. de Klein, J. Stevens, T. Jansen \& G. van Nunen (red.). Écht doen wat nodig is. Pleidooi voor kleinschalige effectieve jeugdhulp, Culemborg: Stichting Beroepseer 2018, p. 13-20.

\section{Hageraats 2018}

R. Hageraats, Eerste evaluatie Jeugdwet. Na de transitie nu de transformatie, Den Haag: ZonMw 2018.

\section{Hermanns 2009}

J. Hermanns, Het opvoeden verleerd (oratie Amsterdam UvA), Amsterdam: Vossius Pers 2009.

\section{Hilhorst \& Zonneveld 2013}

P. Hilhorst \& M. Zonneveld, De gewoonste zaak van de wereld. Radicaal kiezen voor de pedagogische civil society, Den Haag: Raad voor Maatschappelijke Ontwikkeling 2013.

\section{IGJ \& IJenV 2019a}

IGJ \& IJenV, Kwetsbare kinderen onvoldoende beschermd. Toezicht bij de jeugdbescherming en jeugdreclassering, Utrecht: Inspectie Gezondheidszorg en Jeugd en Inspectie Justitie en Veiligheid 2019.

\section{IGJ \& IJenV 2019b}

IGJ \& IJenV, Signalement Kwetsbare kinderen onvoldoende beschermd. Jeugdbeschermingsketen in gevaar, Inspectie Gezondheidszorg en Jeugd en Inspectie Justitie en Veiligheid 2019, www.igj.nl/documenten/ publicaties/2019/11/08/ signalementjeugdbeschermingsketen-ingevaar.

\section{Ince e.a. 2018}

D. Ince, T. van Yperen \& M. Valkestijn, Top 10 beschermende factoren. Voor een positieve ontwikkeling van jeugdigen, Utrecht: Nederlands Jeugdinstituut 2018.

\section{Kesselring 2016}

M. Kesselring, Partners in parenting. A study on shared responsibilities between parents and nonparental adults (diss. Utrecht), Enschede: Ipskamp 2016.

\section{Kesselring 2018}

M. Kesselring, 'Zorgen én ontzorgen. Transformeren van de jeugdhulp door het versterken van de pedagogische civil society', in: D. Graas, A. de Klein, J. Stevens, T. Jansen \& G. van Nunen (red.), Écht doen wat nodig is. Pleidooi voor kleinschalige effectieve jeugdhulp, Culemborg: Stichting Beroepseer 2018, p. 109-115. 


\section{Kesselring 2019}

M. Kesselring, 'De kracht van verbinding. Een sterke basis als fundamenteel ingrediënt in de zorg voor jeugd', Ouderschapskennis (22) 2019, afl. 3, p. 15-21.

\section{Kesselring e.a. 2013}

M. Kesselring, M. de Winter, B. Horjus \& T. van Yperen, 'Allemaal opvoeders in de pedagogische civil society. Naar een theoretisch raamwerk van een ander paradigma voor opgroeien en opvoeden', Pedagogiek (33) 2013, p. 5-20.

\section{Lerner e.a. 2005}

R.M. Lerner, J.B. Almerigi, C. Theokas \& J.V. Lerner, 'Positive youth development: A view of the issues', Journal of Early Adolescence (25) 2005, p. 10-16.

\section{NJi 2018}

NJi (2018). Opvoeden in Nederland, Utrecht: Nederlands Jeugdinstituut 2018, www.nji.nl/nl/

Databank/Cijfers-over-jeugd-enOpvoeding/ (313807)-Cijfers-peronderwerp-Opvoeden.

\section{NJi 2019a}

NJi, Wat is het verschil tussen jeugdzorg en jeugdhulp?, Utrecht: Nederlands Jeugdinstituut 2019, www.nji.nl/nl/Kennis/

Publicaties/Wat-is-het-verschiltussen-jeugdzorg-en-jeugdhulp.

\section{NJi 2019b}

NJi, Goede jeugdhulp is meer dan een kwestie van geld, Utrecht: Nederlands Jeugdinstituut 2019, www.nji.nl/nl/Actueel/Nieuwsvan-het-NJi/Goede-jeugdhulpis-meer-dan-een-kwestie-vangeld.

\section{Putnam 2000}

R.D. Putnam, Bowling alone: The collapse and revival of American Community, New York: Simon \& Schuster 2000.

\section{Van Regenmortel 2015}

M.R.F. van Regenmortel, 'Empowerment en (maatschappelijk) opvoeden', in: C. Gravesteijn \& M. Aartsma (red.), Meer dan opvoeden: perspectieven op het werken met ouders, Bussum: Coutinho 2015.

\section{Resnick e.a. 1997}

M.D. Resnick, P.S. Bearman, R.W. Blum, K.E. Bauman, K.M. Harris, J. Jones e.a., 'Protecting adolescents from harm. Findings from the national longitudinal study on adolescent health', Journal of the American Medical Association (278) 1997, afl. 10, p. 823-832.

\section{Rijksoverheid 2019}

Rijksoverheid, Extra geld voor jeugdzorg en geestelijke gezondheidszorg, 2019, www.rijksoverheid.nl $>$ atueel $>$ nie uws $>2019 / 05 / 27>$ extra-geldvoor-jeugdzorg-engeestelijkegezondheidszorg. 


\section{RMO 2001}

RMO, Aansprekend opvoeden: balanceren tussen steun en toezicht, Den Haag: Raad voor Maatschappelijke Ontwikkeling 2001.

\section{RMO 2009}

RMO, De wijk nemen. Een subtiel samenspel van burgers, maatschappelijke organisaties en overheid, Den Haag: Raad voor Maatschappelijke Ontwikkeling 2009.

\section{RMO 2011}

RMO, Bevrijdend kader voor de jeugdhulp (Briefadvies RMO), Den Haag: Raad voor Maatschappelijke Ontwikkeling 2011.

\section{RMO 2012}

RMO, Ontzorgen en normaliseren. Naar een sterke eerstelijns jeugd- en gezinszorg, Den Haag: Raad voor Maatschappelijke Ontwikkeling 2012.

\section{Scales e.a. 2001}

P.C. Scales, P.L. Benson, E.C. Roehlkepartain, N.R. Hintz, T.K. Sullivan \& M. Mannes, 'The role of neighborhood and community in building developmental assets for children and youth. A national study of social norms among American adults', Journal of Community Psychology (29) 2001, afl. 6, p. 703-729.

\section{Seligman e.a. 2007}

M.E.P. Seligman, K. Reivich, L. Jaycox \& J. Gillham, The optimistic child, New York: Mariner Books 2007.

\section{Stevens e.a. 2018}

G. Stevens, S. van Dorsselaer, M. Boer, S. de Roos, E. Duinhof, T. ter Bogt e.a., HBSC 2017. Gezondheid en welzijn van jongeren in Nederland, Utrecht: Universiteit Utrecht 2018.

\section{Stevens 2019}

J. Stevens, 'Wat was de bedoeling van de Jeugdwet?', in: D. Graas, A. de Klein, J. Stevens, T. Jansen \& G. van Nunen (red.), Écht doen wat nodig is. Pleidooi voor kleinschalige effectieve jeugdhulp, Culemborg: Stichting Beroepseer 2019, p. 21-28.

\section{UNICEF Office of Research 2013}

UNICEF Office of Research, Child well-being in rich countries. $A$ comparative overview (Innocenti Report Card 11), Florence:

UNICEF Office of Research 2013.

\section{VNG 2018}

VNG, Transformatiefonds: 108 miljoen voor vernieuwing jeugdhulp, Den Haag: Vereniging van Nederlandse Gemeenten 2018, www.vng.nl/onderwerpenindex/ jeugdhulp/nieuws/ transformatiefonds-108-miljoenvoor-vernieuwing-jeugdhulp.

\section{VNG 2019}

VNG, Overzicht van de 42 Transformatieplannen Jeugd, Den Haag: Vereniging van Nederlandse Gemeenten 2019, https://vng.nl>files>vng>over zichtsrapportage_transformatie plannen_def. 


\section{De Winter 2008}

M. de Winter, 'Het moderne van kindermishandeling', in:

W. Koops, B. Levering \& M. de Winter (red.), Opvoeding als spiegel van de beschaving, Amsterdam: SWP 2008, p. 150-165.

\section{De Winter 2012}

M. de Winter, Verbeter de wereld, begin bij de opvoeding. Vanachter de voordeur naar democratie en verbinding, Amsterdam: SWP 2012.

\section{De Winter 2017}

M. de Winter, 'De communicerende vaten van jeugdzorg en samenleving', in: S.A.M. Wijsbroek \& M. de Winter, Zorg voor jeugd is veelgevraagd. Over de rol van de jeugdprofessionals in een veranderend (ont)zorglandschap, Utrecht: Hogeschool Utrecht 2017, p. 9-26.

\section{Wijsbroek \& De Winter 2017}

S.A.M. Wijsbroek \& M. de Winter, Zorg voor jeugd is veelgevraagd. Over de rol van de jeugdprofessionals in een veranderend (ont)zorglandschap, Utrecht: Hogeschool Utrecht 2017. 